\title{
EFFICACY OF BAITS FOR RED PALM WEEVIL (RPW), Rhynchophorus ferrugineus OLIVIER UNDER CONSTANT LABORATORY CONDITION
}

\author{
MOHAMAD HARIS-HUSSAIN*; NORMAN KAMARUDIN** and WAHIZATUL AFZAN AZMI
}

\begin{abstract}
Rhynchophorus ferrugineus or also known as red palm weevil (RPW) had caught the attention of government and researchers in Malaysia for its aggressive behaviour in attacking various palm species including coconut palm and date palm. To date, their presence was recorded in oil palm plantations in Terengganu, Malaysia by using pheromone mass trapping technique but no symptom of attack was detected up to now. The pheromone traps were filled with natural food baits such as sugar cane and pineapple, together with synthetic pheromone lure to attract the RPW entering the trap. However, the most preferred bait by the $R P W$ still remained inconclusive. In this study, a Y-tube olfactometer experiment was conducted to identify the most preferred bait by the RPW under laboratory conditions. The result showed that pineapple was the most preferred bait by RPW compared to other treatments ( $F=20.44, d . f=7, p<0.05$ ). The study showed that oil palm cabbage was the least preferred bait by RPW, indicating that the pest was less attracted to oil palm. However, their presence in the oil palm plantation recently gave us a warning that we need to be more cautious to ensure their populations will not jeopardise the oil palm industry in future.
\end{abstract}

Keywords: red palm weevil, Y-tube bioassay, natural food bait, oil palm, pheromone trap.

Date received: 14 March 2019; Sent for revision: 30 May 2019; Accepted: 8 October 2019.

\section{INTRODUCTION}

Red palm weevil (RPW), Rhynchophorus ferrugineus (Coleoptera: Dryophthoridae) is one of the lethal insect pests for cultivated palms worldwide (Faleiro, 2006; Said et al., 2003; Kaakeh et al., 2000). $\mathrm{RPW}$ is reported to attack more than 40 palm

* Department of Biological Sciences and Biotechnology, Faculty of Science and Technology,

Universiti Kebangsaan Malaysia, 43600 Bangi, Selangor, Malaysia.

** Malaysian Palm Oil Board, 6 Persiaran Institusi, Bandar Baru Bangi, 43000 Kajang, Selangor, Malaysia.

₹ Faculty of Science and Marine Environment, Universiti Malaysia Terengganu, 21030 Kuala Nerus, Terengganu, Malaysia.

E-mail:wahizatul@umt.edu.my species belonging to 23 different genera (Hoddle et al., 2016; Malumphy and Moran, 2009; Faleiro, 2006). In Malaysia, RPW populations were recorded and their infestations were first reported in coconut plantation area in Setiu, Terengganu in 2007 (Idris et al., 2014; Wahizatul et al., 2013).

Morphologically, the adult $R$. ferrugineus is reddish-brown with six spots on the thorax (EPPO, 2005) and a conspicuous snout for both sexes. For the male, there is a tuft of hairs on the short snout (Prabhu and Patil, 2009) and for the female, its rostrum is bare, more slender, curved and a little longer than in male (Menon and Pandalai, 1960). Both sexes of this pest have a pair of same shape and size of club-antennae type, which consist of a funicle, a scape and a club, where the sensillae are confined at the extremity of the club (Said et al., 
2003). Referring to Avand-Faghih (2004), the female has more basiconic sensillae on their antenna than male, where this sensillae are the receptors that are sensitive towards pheromone and kairomone odours. The sensing of airborne chemical volatiles by the sensillae provide information for finding mates, locating egg laying sites that the female feels suitable for the larvae to hatch and finding food (Chakravarthy et al., 2014; Hoddle, 2012; Poorjavad et al., 2009). This weevil has strong wings, so that they are capable of attempting long flights (Abbas, 2010).

Early stages of RPW are spent within the tree trunk, during which the weevil destroys vascular system or bores into the heart of the host and eventually causes the tree to collapse and die (Ju et al., 2011). The symptoms are known to be the last stage of RPW attack and also a sign that RPW have already moved out from the damaged trees and spread to other healthy trees. The most worrying part is that when there are less coconut trees, indirectly the huge population of RPW will possibly move to other less preferred but highly abundant host plants particularly oil palm. This is a serious concern since Malaysia has 5.81 million hectares of oil palm plantations (Kushairi et al., 2018).

To date, the presence of RPW in oil palm area indicates a potential threat for the oil palm industry in Malaysia (Idris et al., 2014; Ain-Farhah, 2013). Thus, the best method for capturing the RPW must be applied urgently to prevent them from spreading and slowly devastating the oil palm plantation. According to Al-Saoud et al. (2010), pheromone-based mass trapping system is the best technique and commonly practiced compared to the other techniques. The trapping of RPW can be synergised by adding fermented cut fruit as food bait together with the aggregation pheromone lure (Oehlschlager, 2007; Oehlschlager et al., 1993). The synergy between synthetic pheromone lure and fermented food bait had been proven significantly more effective in capturing RPW adults instead of using the pheromone lure alone (Wahizatul et al., 2014; Faleiro and Satarkar, 2005).

However, a problem arises when using the fermented natural food baits where they cannot last for a long period and the baits need to be replaced every two weeks. The natural baits have to be replaced frequently for a maximum trapping efficacy (Fiaboe et al., 2011; Hallett et al., 1999). Compared to natural food baits, palm attractants are longer lasting which is about one month (Haris et al., 2014). Therefore, the idea of using palm attractants together in pheromone trap seems to be a better alternative in increasing the efficacy of pheromone trapping in encountering RPW population (Guarino et al., 2011). Thus, the objective of this study was to determine the RPW adults' preferences toward bait treatments (natural food baits and synthetic attractants) under laboratory conditions. In this study, it is hypothesised that RPW prefers natural food baits more compared to palm attractants.

\section{MATERIALS AND METHODS}

\section{Preparation of RPW Adult Samples}

This study was conducted under controlled condition in the Ecology Laboratory, Universiti Malaysia Terengganu, Terengganu, Malaysia. The RPW adult samples tested in this experiment were captured around Kuala Nerus area, Terengganu ( $\left.5^{\circ} 19^{\prime} 48.72^{\prime \prime} \mathrm{N}, 103^{\circ} 08^{\prime} 26.88^{\prime \prime} \mathrm{E}\right)$ by using the common practise of RPW pheromone trappings (Chakravarthy et al., 2014; Wahizatul et al., 2014). Collected RPW adult samples from the pheromone traps were kept in the laboratory conditions, at 26 $\pm 0.2^{\circ} \mathrm{C}$ temperature; $75 \%-80 \%$ relative humidity (RH) and photoperiod of 12L: 12D in covered plastic boxes $(10 \mathrm{~cm}$ diameter $x 7 \mathrm{~cm}$ high) in pairs and were fed with pieces of sago palm. The samples were acclimatised for one to two days (24-48 hr) to avoid mortality caused by stress. The samples were then quarantined individually in small plastic containers without any food for one day period prior to the start of the bioassay experiments.

\section{Fabrication of Two-chamber Y-tube Olfactometer}

The behavioural experiment was assessed using a standard glass Y-tube olfactometer (internal diameter, $3 \mathrm{~cm}$; length of arm, $15 \mathrm{~cm}$ ) with two arms extending from the two sides (Cheng et al., 2015) (Figure 1). A transparent Perspex of $3 \mathrm{~mm}$ thickness was used for constructing the square food bait chambers $(20 \mathrm{~cm} \times 20 \mathrm{~cm} \times 20 \mathrm{~cm})$ at the end of both arms of the Y-tube olfactometer. These chambers were specifically designed and modified from previous methods for bait preference experiment (Najar-Rodriguez et al., 2010; Poorjavad et al., 2009; Mackenzie et al., 2008; Van-Tol et al., 2002).

At one side of the chambers, at $10 \mathrm{~cm}$ height from the bottom, a $3 \mathrm{~cm}$ round hole was cut whereas three small rectangle holes were cut at opposite sides of the round hole for both chambers. A rubber rim was placed at each connecting end to provide support to keep the tube in position and to connect with the chambers through the round holes. This also prevented the tube from being pushed inside those chambers.

The three small rectangle holes were used to allow the air flow from the small axial flow fans. These fans were used to provide uniform air flow into the Y-tube and prevented the bait's odour from entering the other chamber (Ranjith, 2007). The distal end of both food bait chambers were 
closed with a removable Perspex sliding door to avoid the odour from flowing into the tube's arms before the experiment began. The lid of the chambers could be opened and closed to place the bait preference inside the chambers $(20 \mathrm{~cm} \mathrm{x}$ $20 \mathrm{~cm}$ ).

\section{Bait Preference List}

Eight treatments were tested in this study in order to identify the most preferred bait by the RPW adults under laboratory condition (Table 1). Four of the treatments were $300 \mathrm{~g}$ of natural food baits (whole part of the ripe, mature plants and cabbages were used as the treatments) which consisted of pineapple, sugar cane, coconut and oil palm, while the remaining four treatments were $300 \mathrm{ml}$ of palm attractants (ethyl acetate, ethyl butyrate, ethyl propionate and ethylene glycol). The selected treatments were chosen based on previous potential palm attractants (Guarino et al., 2011; GiblinDavis et al., 1996) and baited pheromone trap field experiment (Haris et al., 2014; Wahizatul et al., 2014; Hoddle and Hoddle, 2011; Faleiro and Satarkar, 2005).

\section{RPW Preference Bioassay}

All the apparatus were based on the previous standard procedure of preference bioassay experiment (Cheng et al., 2015) (Figure 1). This experimental design was following the previous standard method for RPW as test subject by Poorjavad et al. (2009). An individual adult RPW was placed in the base (terminal end) of the Y-tube olfactometer to begin the experiment. The bait tested was placed in one chamber of the olfactometer while another chamber was left empty which acted as control. If the RPW remained motionless for $15 \mathrm{~min}$, it was classified as a non-mover and the assay was terminated. The assay would also be stopped when the individual had made a choice (entered the jar for more than $1 \mathrm{~min}$ ) or after $30 \mathrm{~min}$ if it did not make any choice. One hundred individuals of the RPW adults were used in this experiment (50 males and 50 females) for all preference bioassay experiments which were then divided into 10 replicates. Each replicate consisted of 10 individuals of RPW. After each assay, the tube and chambers were washed and cleaned by alcohol and rotated $180^{\circ}$ before starting a new assay.

TABLE 1. TYPE OF BAITS USED IN THIS STUDY

\begin{tabular}{ll}
\hline Preferences & Name of bait $(\mathrm{g}$ or $\mathbf{~ m l})$ \\
\hline Natural food baits & Sugar cane, Saccharum officinarum $(300 \mathrm{~g})$ \\
& Pineapple, Ananas comosus $(300 \mathrm{~g})$ \\
& Coconut cabbage, Cocos nucifera $(300 \mathrm{~g})$ \\
& Oil palm cabbage, Elaeis guineensis $(300 \mathrm{~g})$ \\
Palm attractants & Ethylene glycol, $\mathrm{C}_{2} \mathrm{H}_{6} \mathrm{O}_{2}(300 \mathrm{ml})$ \\
& Ethyl propionate, $\mathrm{C}_{5} \mathrm{H}_{10} \mathrm{O}_{2}(300 \mathrm{ml})$ \\
& Ethyl butyrate, $\mathrm{C}_{6} \mathrm{H}_{12} \mathrm{O}_{2}(300 \mathrm{ml})$ \\
& Ethyl acetate, $\mathrm{C}_{4} \mathrm{H}_{8} \mathrm{O}_{2}(300 \mathrm{ml})$ \\
\hline
\end{tabular}

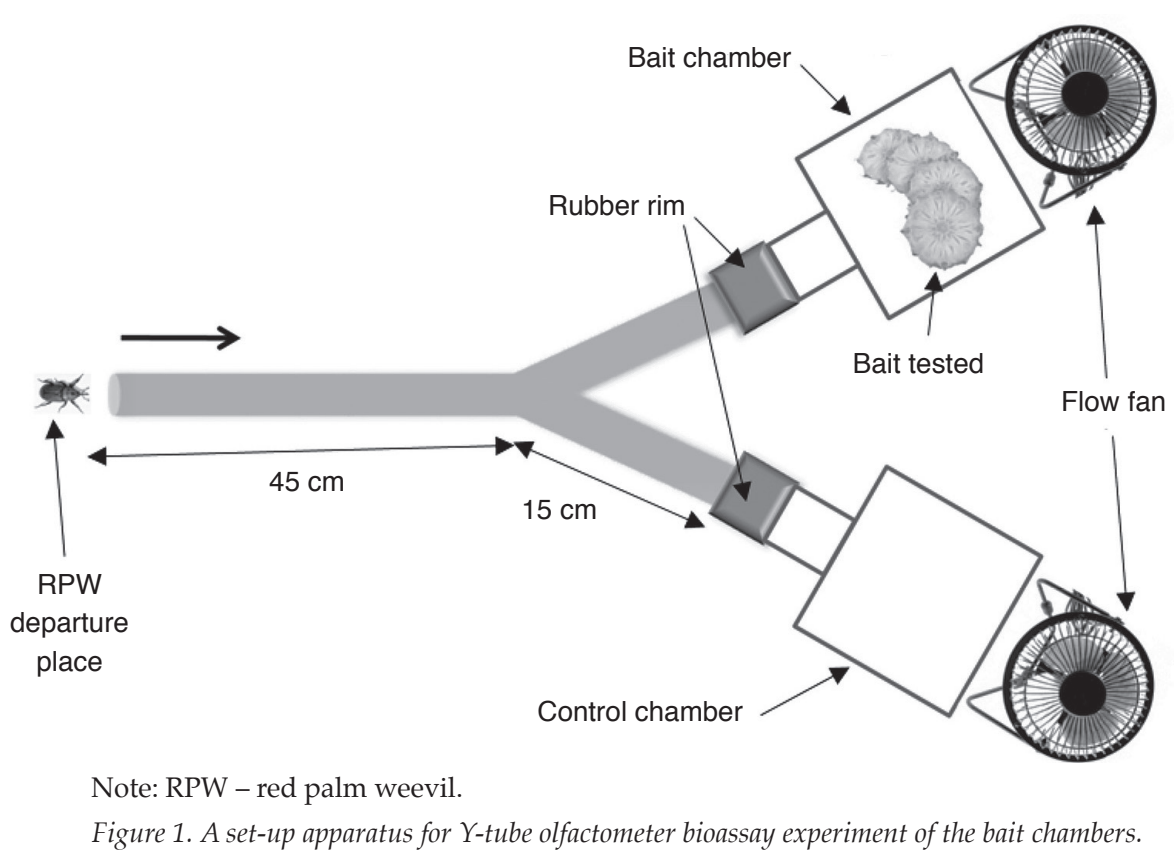




\section{Statistical Analysis}

The normality of dataset was tested by using Shapiro-Wilk W Test $(p>0.05)$ and the result was normally distributed. Then, the differences between the treatment means were subjected to one-way analysis of variance (ANOVA). As the ANOVA result was significant $(p<0.05)$, means were separated using Tukey's test at $p<0.05$. The mean data collected based on sexes were tested with independent sample T-test analysis to compare the differences between both sexes of RPW adult responses toward the selected treatment. Chi-

TABLE 2. A THREE-WAY ANALYSIS OF VARIANCE (ANOVA) TESTING FOR THE EFFECT OF TREATMENT, SEX AND CHOICE FACTORS ON THE MEAN OF CATCHES THROUGHOUT THE SAMPLING PERIOD

\begin{tabular}{lcc}
\hline Source & Df & F \\
\hline Treatment & 7 & 0.028 \\
Sex & 1 & 0.028 \\
Choice & 2 & $48.626^{*}$ \\
Treatment $x$ sex & 7 & 0.028 \\
Treatment $x$ choice & 14 & $14.116^{*}$ \\
Sex x choice & 2 & $34.036^{*}$ \\
Treatment $x$ sex $x$ choice & 14 & 1.366 \\
\hline
\end{tabular}

Note: Levels of significance: ${ }^{*} \mathrm{p}<0.05$.

Df - degrees of freedom.

$\mathrm{F}$ - $\mathrm{F}$ values (for ANOVA). square analysis $\left(\mathrm{X}^{2}\right)$ was used to determine the differences in the number of RPW adults entering either treatment or control chamber (two-choices). A three-way ANOVA was tested to determine the interaction between all factors. All the statistical analyses carried out in this study used the statistical software of Statistical Package for the Social Sciences (SPSS), Version 23.0.

\section{RESULTS}

Interaction of Findings among Bait Treatments, RPW Sexes and Choices Factors on RPW Preferences

Based on the analysed result, there was no significant three-way interaction for treatment, sex and choice on RPW preferences (ANOVA, p > 0.05) (Table 2). Only factors of choice, treatment $x$ choice and sex $x$ choice showed a significant interaction among them $(\mathrm{p}<0.05)$.

\section{Responses of RPW Adults toward Several Types of Bait}

In this study, RPW adults preferred more on natural food bait (specifically pineapple) compared to synthetic attractants (Figure 2). The pineapple attracted the highest percentage of RPW responses

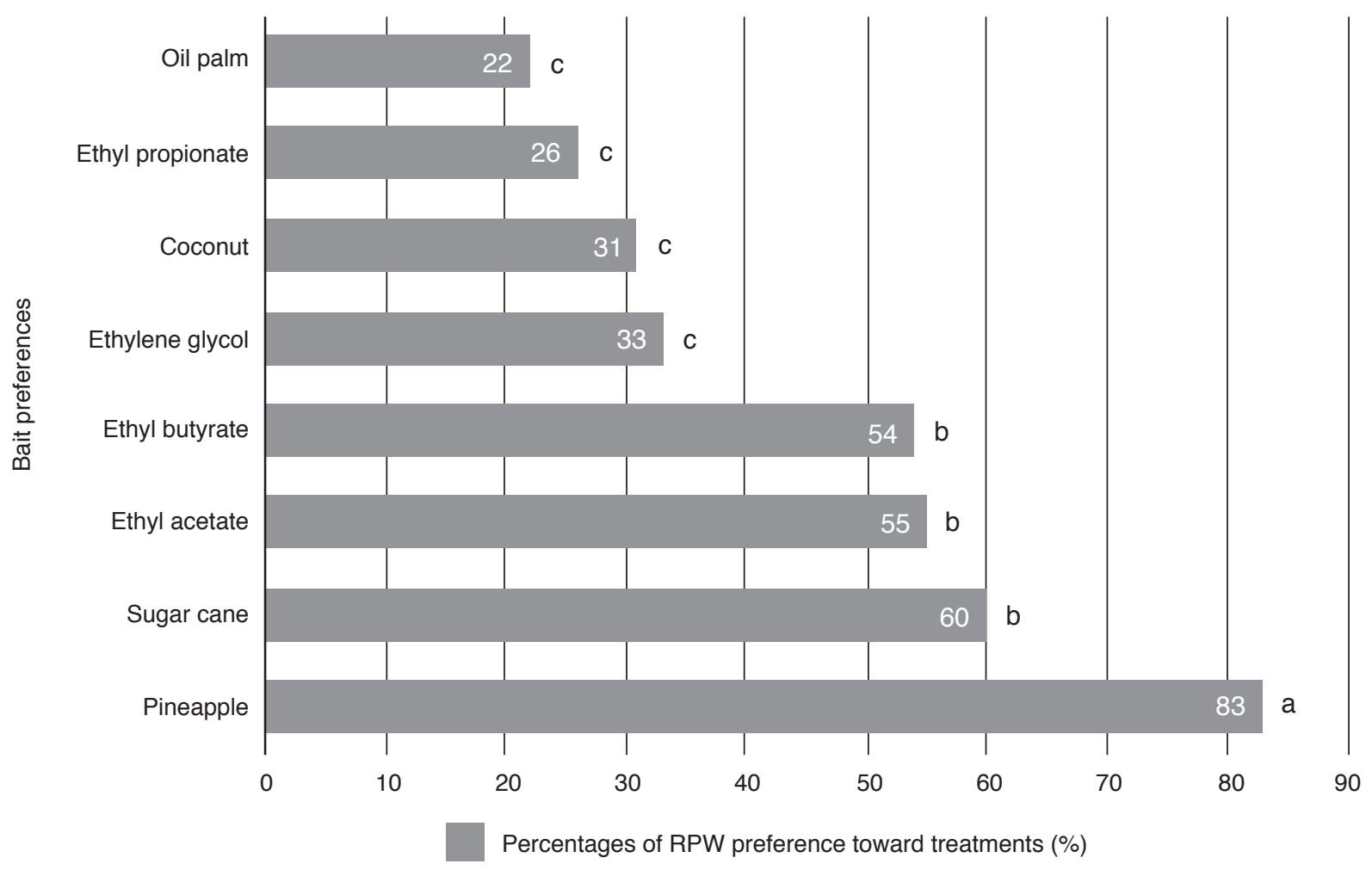

Figure 2. Percentages of red palm weevil (RPW) adult preference toward different bait preferences. Bars with the same letter indicate no significant difference $(p>0.05)$. 
$(83 \%)$ and was significantly greater than other treatments $(\mathrm{F}=20.44$, d.f. $=7$, $\mathrm{p}<0.05)$. The second highest bait preferences was sugar cane $(60 \%)$, followed by ethyl acetate (55\%) and ethyl butyrate $(54 \%)$ but not significantly difference among the three of them $(\mathrm{p}>0.05)$.

On the contrary, oil palm showed the least preferred bait by the RPW (22\%), which was not significantly different from ethyl propionate $(26 \%)$, coconut $(31 \%)$ and ethylene glycol $(33 \%)$. Even though there were some potential synthetic attractants like ethyl acetate and ethyl butyrate to be used as bait replacement in RPW pheromone trap, the natural food baits (pineapple) seemed to be more preferable compared to the synthetic attractants.

\section{Bait Preference of RPW Adults Based on Sexes}

The preferences of the RPW adults toward various kind of baits was significantly different based on sexes. More than half of the RPW adults that responded were female $(63 \%)$ compared to male $(37 \%)$ as in Figure 3. The overall ratio between male and female for this study was 1:1.72, where both sexes were significantly different between each other $(\mathrm{F}=0.034$; d.f. $=14 ; \mathrm{p}<0.05)$ (Table 3$)$. Both male and female of the RPW adults showed significant preferences toward pineapple bait than other treatments.

Majority of the female weevils had responded significantly $(p<0.001)$ to the food bait compared to male weevils especially for the treatments of pineapple, sugar cane, ethyl acetate and ethyl butyrate. Meanwhile, the preferences of male weevils towards coconut, oil palm, ethylene glycol and ethyl propionate were significantly low $(p<0.05)$. However, male weevils showed no significant interest $(p>0.05)$ to the sugar cane, ethyl acetate and ethyl butyrate. Female weevils also did not show any significant preference to either coconut, ethylene glycol or ethyl propionate.

\section{DISCUSSION}

In this study, it was clear that the responses of RPW adults significantly differed according to the various kind of baits. As these experiments were under controlled condition, the result would become an indicator for other researchers to choose the best food bait for the RPW pheromone trap. There were many previous studies that came out with various effective natural food bait such as sugar cane (Faleiro and Satarkar, 2005; Oehlschlager et al., 2002), pineapple (Wahizatul et al., 2014), date fruit (Kaakeh et al., 2000) and possible synthetic attractants like ethyl acetate (Hoddle and Hoddle, 2011) and ethylene glycol (Haris et al., 2014). The influence of these treatments towards RPW were already tested by using electroantennography in previous studies conducted by various researchers (Giblin-Davis et al., 1994; Rochat et al., 1991; Guarino et al., 2011).

RPW adults obviously preferred pineapple in natural food bait category compared to synthetic

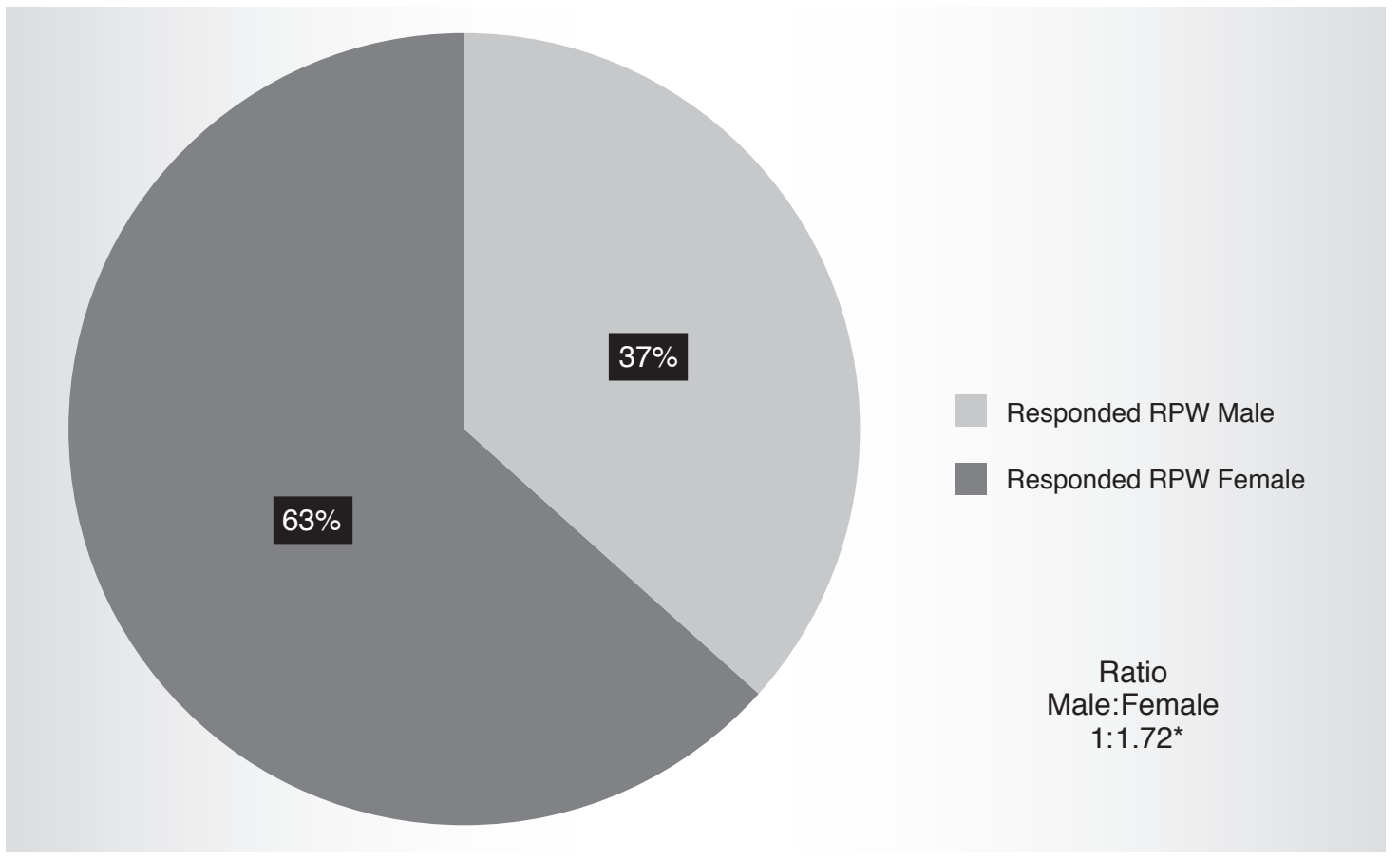

Figure 3. Percentage and ratio number of red palm weevil (RPW) adults responded to the treatments based on sexes. $\left.{ }^{*}\right)$ Showed there was a significant difference between number of male and female that responded toward treatment $(p<0.05)$. 
TABLE 3. THE NUMBER OF RED PALM WEEVIL (RPW) ADULT PREFERENCES TO THE TREATMENT CHOICE IN Y-TUBE OLFACTOMETER EXPERIMENT AFTER $30 \mathrm{~min}$ PER INDIVIDUAL ACCORDING TO THE SEX ( $\mathbf{N}=100$ individuals $)$

\begin{tabular}{|c|c|c|c|c|}
\hline Treatments & Sex & No choice & \multicolumn{2}{|c|}{ Choice } \\
\hline Pineapple & Male & 1 & $40^{* * *}$ & 9 \\
\hline \multirow[t]{2}{*}{ Sugar cane } & Male & 11 & $21 \mathrm{~ns}$ & 18 \\
\hline & Female & 7 & $39^{* * *}$ & 4 \\
\hline Coconut cabbage & Female & 8 & $21 \mathrm{~ns}$ & 21 \\
\hline \multirow[t]{2}{*}{ Oil palm cabbage } & Male & 15 & 7 & $28^{* \star *}$ \\
\hline & Female & 13 & $15 \mathrm{~ns}$ & 22 \\
\hline Ethyl acetate & Male & 17 & $19 \mathrm{~ns}$ & 14 \\
\hline \multirow[t]{2}{*}{ Ethylene glycol } & Male & 15 & 8 & $27^{* *}$ \\
\hline & Female & 6 & $25 \mathrm{~ns}$ & 19 \\
\hline \multirow[t]{2}{*}{ Ethyl propionate } & Male & 19 & 8 & $23^{* *}$ \\
\hline & Female & 13 & $18 \mathrm{~ns}$ & 19 \\
\hline
\end{tabular}

Note: The differences of RPW responses toward treatment compared to the control ( $\chi^{2}$ test) based on sexes were measured by: ns - no significant difference, $\left({ }^{*}\right)$ denoted there was a significant difference at $0.05,\left({ }^{* *}\right)$ showed a significant difference at 0.01 , while ${ }^{* * *}$ indicated a very significant difference at 0.001 .

attractants in this study (Figure 2). This result can be supported from a study done by GiblinDavis et al. (1997) at Palermo where they found that the effect of natural fermenting plant tissues was significantly better compared to volatile components in attracting RPW to a pheromone trap. None of the synthetic attractants had been as effective as palm tissue in enhancing pheromonal attractiveness (Giblin-Davis et al., 1996). This situation is also similar with the wounded, damaged or dying host plant in the field where high sugar content has accumulated at that affected part and indirectly provide olfactory cues in attracting the RPW (Giblin-Davis et al., 1996). Among those natural food baits tested in the bioassay study, pineapple showed the best bait preferred by both male and female RPW (Table 3).

Current study also lends support to the findings from previous pheromone trapping study in Malaysia by Wahizatul et al. (2014) that pineapple was the most effective food bait to be selected whether in field or in laboratory conditions. There are several major volatile compounds produced during the pineapple fermentation process, such as acetaldehyde, methanol, 2-methyl-1propanol, 3-methyl-1-butanol, 2-phenylethanol, propyl butyrate and ethyl acetate (Luciana et al., 2015). All of the volatile components play important role in making the fermented pineapple attractive, especially for the insects. For example, 2-phenylethanol has aromatic descriptions like 'sweet', 'perfume-like' and this odour can influence the aroma of fermented pineapple (Falque et al., 2001). Besides alcohol scent in pineapple, palm ester from the fermented pineapple emits the sweet and fruity aroma that attracts more RPW (Rita et al., 2011). For pineapple, ethyl acetate is one of the esters detected in previous study by using gas chromatography method, while high sugar content is one of the important factors in influencing the concentrations of the esters (Luciana et al., 2015).

Another volatile compound that is produced in pineapple is ethylene glycol. It is produced in pineapple during vegetative maturity which enhances the pineapple to undergo flowering and fruiting cycle (NOSB, 2007). Luciana et al. (2015) reported low concentrations of volatile acid compounds in fermented pineapple, which were short-chain fatty acids (isobutyric and butyric acid). The odour of these volatile acids may be strong and described as 'sweet' and 'bitter' and contributes significantly to the pineapple scent (Meilgaard, 1975). Thus, the complex structure of fermented pineapple itself, which consists of many major volatile compounds, could be the main reason why pineapple was the most preferred food bait by RPW among other food baits.

Oil palm bait treatment was the least preferred by RPW. This is in agreement with the previous field trapping study conducted by Faleiro and Satarkar 
(2005) where oil palm was the least preferred attractant in pheromone trap and not effective in capturing the weevil. The fact that oil palm has less sugar content compared to pineapple and sugar cane, is possibly the main factor that the RPW was least attracted to the oil palm food bait (Yamada et al., 2010).

The use of synthetic attractants such as ethyl acetate to increase the efficiency of the pheromonebaited traps was indeed significantly effective in attracting the weevil (Al-Saoud, 2013). Based on the behavioural experiment, there were some potential synthetic attractants, ethyl acetate and ethyl butyrate, which can be used to replace the natural food baits. Among the tested attractants, ethyl acetate was the most preferred by the RPW. This finding is supported by Guarino et al. (2011) who reported that ethyl acetate produced from fermenting palm tissues can attract more RPW into the traps. Field trapping study conducted by Hoddle and Hoddle (2015) also had named ethyl acetate as 'weevil magnet' because of its effectiveness in capturing the weevils.

Besides that, another potential attractant to be used for bait replacement in trap is ethylene glycol. In terms of the most preferred attractants for field study with less evaporation and longerlasting, ethylene glycol was recorded to be the best preference compared to ethyl acetate, ethanol and control (no treatment) as in previous research by Haris et al. (2014). However, when tested under controlled condition in laboratory, ethylene glycol was the least preferred compared to ethyl acetate and ethyl butyrate.

This study also revealed that without the disturbance factor in the field, ethyl acetate can attract more RPW into the trap rather than using ethylene glycol. Therefore, it is suggested that ethyl acetate could also be used to increase the pheromone trapping efficacy. In spite of having the potential attractants to be used in capturing RPW, the attractants to stand alone as the pheromone trap's bait replacement seems to be not feasible for now.

The efficacy of synthetic attractants is still considered low compared with natural food baits. Still, the attractants can be used to increase the synergisation with the pheromone and natural bait (Wahizatul et al., 2014), but not as a bait replacement by itself. Many studies had been conducted previously regarding different responses to preference by sex for other beetle species (Robert and Bohlmann, 2010; Graaf et al., 2005; White and Chambers, 1989). A previous report on weevil Rhynchophorus palmarum showed that sex factor did not affect the response (Rochat et al., 1991). However, for $R$. ferrugineus, there was a significantly higher response of females compared to males toward preference in this experiment.
This current result is supported by Poorjavad et al. (2009) where they found that RPW females showed a significantly more responses than males. The study also suggested that females might have higher sensitivity than males toward baits. This is in agreement with Avand-Faghih (2004) who suggested that RPW females have more basiconic sensillae on their antenna than males. Another reason why female highly responded than male was because female had higher activity levels than male. This high activity level has benefited the female to easily get influenced by the surrounding factors such as better breeding sites, potential mate and also predator compared to male weevil (Chakravarthy et al., 2014; AvandFaghih, 1998).

\section{CONCLUSION}

Pineapple was the most effective food bait in RPW pheromone trapping since it was the most preferred food bait and oil palm the least. The synthetic attractants need more modification to increase their effectiveness whether to be in the same level or surpass the effectiveness of natural food baits. Although the natural food baits are not long lasting compared to the attractants when used in field trapping, they are still the best component (acted as kairomone) to synergise with synthetic RPW pheromone lure which is 4-methyl-5-nonanol. Thus, for the future maximum pheromone trapping efficacy, it is suggested to use the combination of natural food bait and synthetic attractants, which are pineapple+ethyl acetate or pineapple+ethyl butyrate. This new synergisation of RPW specific pheromone with natural food bait and synthetic attractants will be a new combination to trap more RPW. In spite of the latest pheromone trapping formulation, it is suggested that a similar behavioural experiment for RPW under controlled condition should be done periodically in the future to monitor the insect behaviour towards oil palm especially when the beetles are devoid of feeding materials from coconut.

\section{ACKNOWLEDGEMENT}

The authors would like to express their gratitude to the Director-General of MPOB for permission to publish this article. Thanks also to the Ministry of Education Malaysia, for providing Research Acculturation Collaborative Effort (RACE) grant (vot: 56010) and MPOB for sponsoring Graduate Student Assistantship Scheme (GSAS). Special thanks to the Universiti Malaysia Terengganu, MPOB and Department of Agriculture for the assistance in conducting this research. 


\section{REFERENCES}

Abbas, M S T (2010). IPM of the red palm weevil, Rhynchophorus ferrugineus. J. Plant Protection Research, 9: 209-230.

Ain-Farhah, N R S K (2013). Influence of Pheromone Based-mass Trapping System on Red Palm Weevil, Rhynchophorus ferrugineus (Coleoptera: Curculionidae) in Selected Federal Land Development Authority (FELDA) Oil Palm Plantations in Terengganu. B.Sc. thesis, Universiti Malaysia Terengganu. 45 pp.

Al-Saoud, A H (2013). Effect of ethyl acetate and trap colour on weevil captures in red palm weevil Rhynchophorus ferrugineus (Coleoptera: Curculionidae) pheromone traps. Int. J. Trop. Insect Sci., 1: 1-5.

Al-Saoud, A H; Al-Deeb, M A and Murchie, A K (2010). Effect of colour on the trapping effectiveness of red palm weevil, Rhynchophorus ferrugineus (Coleoptera: Curculionidae) pheromone traps. J. Entomol., 7(1): 54-59.

Avand-Faghih, A (1998). Research on the Control of Red Palm Weevil, Rhynchophorus ferrugineus in Sistan and Balouchestan Province (Iran). M.Sc. thesis, University of Tehran. 90 pp.

Avand-Faghih, A (2004). Identification et application agronomique de synergistes vegetaux de la pheromone $d u$ charancon Rhynchophorus ferrugineus (Olivier). Ph.D thesis, Institute National Agronomique ParisGrignon et Institute National de la Recherche Agronomique, France. 150 pp.

Chakravarthy, A K; Chandrashekharaiah, M; Kandakoor, S B and Nagaraj, D N (2014). Efficacy of aggregation pheromone in trapping red palm weevil (Rhynchophorus ferrugineus Olivier) and rhinoceros beetle (Oryctes rhinoceros Linn.) from infested coconut palms. J. Environ. Biol., 35: 479-484.

Cheng, Y; Ulyshen, M D and Poland, T M (2015). Abundance of volatile organic compounds in white ash phloem and emerald ash borer larval frass does not attract Tetrastichus planipennisi in a Y-tube olfactometer. J. Insect Sci., 23: 712-719.

European and Mediterranean Plant Protection Organization (EPPO) (2005). Data sheets on quarantine pests - Rhynchophorus palmarum. EPPO Bulletin, 35: 468-471.

Faleiro, J R (2006). A review of the issues and management of the red palm weevil Rhynchophorus ferrugineus (Coleoptera: Rhynchophoridae) in coconut and date palm during the last one hundred years. Int. J. Trop. Insect Sci., 26(3): 135-154.
Faleiro, J R and Satarkar, V R (2005). Attraction of food baits for use in red palm weevil Rhynchophorus ferrugineus Olivier pheromone trap. Indian J. Plant Prot., 33(1): 23-25.

Falque, E; Fernandez, E and Dubourdieu, D (2001). Differentiation of white wines by their aromatic index. J. Talanta, 54: 271-281.

Fiaboe, K K M; Mankin, R W; Roda, A L M T K and Johanns, C (2011). Pheromone-food-bait and acoustic surveys of Rhynchophorus ferrugineus (Coleoptera: Curculionidae) in Curacao. Florida Entomol., 94(4): 766-773.

Giblin-Davis, R M; Gries, R; Gries, G; Pena-Rojas, E; Pinzon, I; Pena, J E; Perez, A L; Pierce, H D Jr and Oehlschlager, A C (1997). Aggregation pheromone of palm weevil, Dynamis borassi. J. Chem. Ecol., 23(10): 2287-2297.

Giblin-Davis, R M; Oehlschlager, A C; Perez, A; Gries, G; Gries, R; Weissling, T J; Chincilla, C M; Pena, J E; Hallett, R H; Pierce, H D Jr and Gonzalez, L M (1996). Chemical and behavioral ecology of palm weevils (Curculionidae: Rhynchophorinae). Florida Entomol., 79: 153-167.

Giblin-Davis, R M; Weissling, T J; Oelschlager, A C and Gonzales, L M (1994). Field response of Rhynchophorus cruentatus F. (Coleoptera: Curculionidae) to its aggregation pheromone and fermenting plant volatiles. Florida Entomol., 77: 164-177.

Graaf, J; Govender, P; Schoemen, A S and Viljoen, A (2005). Efficacy of pheromone seasonal trapping of the banana weevil, Cosmopolites sordidus in South Africa. Int. J. Pest Manage., 51(3): 209-218.

Guarino, S; Lo, B P; Peri, E and Colazza, S (2011). Responses of Rhynchophorus ferrugineus adults to selected synthetic palm esters: Electroantennographic studies and trap catches in an urban environment. Pest Manage. Sci., 67: 77-81.

Hallett, R H; Oehlschlager, A C and Borden, J H (1999). Pheromone trapping protocols for the Asian palm weevil, Rhynchophorus ferrugineus (Coleoptera: Curculionidae). Int. J. Pest Manage., 45(3): 231-237.

Haris, M H; Nang, M L S; Chuah, T S and Wahizatul, A A (2014). The efficacy of synthetic food baits in capturing red palm weevil, Rhynchophorus ferrugineus (Coleoptera: Curculionidae) in campus area of Universiti Malaysia Terengganu. Serangga, 19(1): 59-78.

Hoddle, M S (2012). Testing a New Trapping Program for Red Palm Weevil in Laguna Beach, California. Centre for Invasive Species Research. p. 1-29. 
Hoddle, C D and Hoddle, M S (2015). Evaluation of three trapping strategies for the palm weevil, Rhynchophorus vulneratus (Coleoptera: Curculionidae), in Sumatra, Indonesia. Pak. Entomol., 37(2): 73-77.

Hoddle, M S and Hoddle, C D (2011). Evaluation of three trapping strategies for red palm weevil, Rhynchophorus ferrugineus (Coleoptera: Curculionidae) in the Philippines. Pak. Entomol., 33(2): 77-80.

Hoddle, MS; Hoddle, CD;Alzubaidy, M; Kabashima, J; Nisson, J N; Millar, J and Dimson, M (2016). Palm weevil Rhynchophorus vulneratus eradicated from Laguna Beach. Calif. Agri., 71(1): 1-7.

Idris, A B; Mokhtaruddin, H; Zazali, C; NurulWahida, O; Yaakop, S and Hazmi, I R (2014). The potential of red palm weevil infesting and destroying oil palm industry in Malaysia. The Planter, 90(1058): 329-335.

Ju, R; Wang, F; Wan, F and Li, B (2011). Effect of host plants on development and reproduction of Rhynchophorus ferrugineus (Olivier) (Coleoptera: Curculionidae). J. Pest Science, 84(1): 33-39.

Kaakeh, W; El-Ezaby, F; Aboul-Nour, M M and Khamis, A A (2000). Management of Red Palm Weevil, Rhynchophorus ferrugineus Olivier, by $A$ Pheromone/Food-based Trapping System. Department of Plant Production, United Arab Emirates University. 19 pp.

Kushairi, A; Soh, K L; Azman, I; Hishamuddin, E; Ong-Abdullah, M; Izuddin, Z B M N; Razmah, G; Sundram, S and Parveez, G K A (2018). Oil palm economic performance in Malaysia and $R \& D$ progress in 2017. J. Oil Palm Res. Vol. 30(2): 163-195.

Luciana, S R; Whasley, F D; Disney, R D and Rosane, F S (2015). Fermented sugarcane and pineapple beverage produced using Saccharomyces cerevisiae and non-Saccharomyces yeast. J. Ins. Brew., 121: 262-272.

Mackenzie, J K; Landolt, P J and Zack, R S (2008). Sex attraction in Polistes dominulus (Christ) demonstrated using olfactometers and morphological source extracts. J. Entomol. Soc. Br. Columbia, 105: 35-43.

Malumphy, C and Moran, H (2009). Plant pest fact sheet: Red palm weevil (Rhynchophorus ferrugineus). The Food and Environment Research Agency (Fera), (50): 1-3.

Meilgaard, M C (1975). Flavor chemistry of beer: Part II: Flavor and threshold of 239 aroma volatiles. MBAA Tech. Quart., 12(3): 151-168.
Menon, K P V and Pandalai, K M (1960). Pests in the Coconut Palm. Indian Central Coconut Committee, Ernakulam. p. 261-265.

Najar-Rodriguez, A J; Galizia, C G; Stierle, C G and Dom, S (2010). Behavioural and neurophysiological responses of an insect in host plant-derived volatile mixtures. J. Exp. Biol., 213: 3388-3397.

NOSB (National Organic Standards Board) (2007). Ethylene. http:/ / www.ams.usda.gov/ AMSv1.0/ge tfile?dDocName=STELPRDC5067073, accessed on 2 January 2017.

Oehlschlager, A C (2007). Optimizing trapping of palm weevils and beetles. Acta Horti., 736: 347-368.

Oehlschlager, A C; Chinchilla, C; Castillo, G and Gonzalez, L (2002). Control of red ring disease by mass trapping of Rhynchophorus palmarum (Coleoptera: Curculionidae). J. Fla. Entomol., 85(3): 507-513.

Oehlschlager, A C; Chinchilla, C M; Gonsales, L M; Jifron, L F; Mexzon, L and Morgan, B (1993). Development of a pheromone based trap for American palm weevil Rhynchophorus palmarum (Coleoptera: Curculionidae). J. Econ. Entomol., 86: 1381-1392.

Poorjavad, N; Goldansaz, S H and AvandFaghih, A (2009). Response of the red palm weevil Rhynchophorus ferrugineus to its aggregation pheromone under laboratory conditions. Bull. Insectol., 62(2): 257-260.

Prabhu, S T and Patil, R S (2009). Studies on the biological aspects of red palm weevil, Rhynchophorus ferrugineus (Oliv.). Karnataka J. Agri. Sci., 22(3): 732733.

Ranjith, A M (2007). An inexpensive olfactometer and wind tunnel for Trichogramma chilonis Ishii (Trichogramma: Hymenoptera). J. Trop. Agri., 45(12): 63-65.

Rita, R; Zanda, K; Daina, K and Dalja, S (2011). Compositions of aroma compounds in fermented apple juice; effect of apple variety, fermentation temperature and inoculated yeast concentration. Proc. Food Sci., 1: 1709-1716.

Robert, J A and Bohlmann, J (2010). Behavioral and reproductive response of white pine weevil (Pissodes strobe) to resistant and susceptible Sitka spruce (Picea sitchensis). J. Insects, 1: 3-19.

Rochat, D; Gonzalez, V; Mariau D; Villanueva, A and Zagatti, A (1991). Evidence for male produced 
aggregation pheromone in American palm weevil, Rhynchophorus palmarum (L.) (Coleoptera: Curculionidae). J. Chem. Ecol., 17(6): 1221-1230.

Said, I; Tauban, D; Renou, M; Mori, K and Rochat, D (2003). Structure and function of antennal sensilla of the palm weevil Rhynchophorus palmarum (Coleoptera, Curculionidae). J. Insect Physiol., 49: 857-872.

Van-Tol, R W H M; Visser, J H and Sabelis, M W (2002). Olfactory responses of the vine weevil, Otiorhynchus sulcatus, to tree odours. J. Physiol. Entomol., 27: 213-222.

Wahizatul, A A; Shahrol, N Z; Haris, M H; Yong, K W; Zazali, C and Ahmad, S S (2014). Field trapping of adult red palm weevil Rhynchophorus ferrugineus Olivier (Coleoptera: Curculionidae) with food baits and synthetic pheromone lure in a coconut plantation. Philippine Agri. Sci., 97(4): 409-415.

Wahizatul, A A; Zazali, C; Abdul, R A R and Nurul, I A G (2013). A new invasive coconut pest in Malaysia: The red palm weevil (Curculionidae: Rhynchophorus ferrugineus). The Planter, 89: 97-110.

White, R P and Chambers, J (1989). Saw-toothed grain beetle Oryzaephilus surinamensis (L.) (Coleoptera: Silvanidae) antennal and behavioural responses to individual components and blends of aggregation pheromone. J. Chem. Ecol., 15(3): 1015-1031.

Yamada, H; Tanaka, R; Sulaiman, O; Hashim, R; Hamid, Z A A; Yahya, M K A; Kosugi, A; Arai, T; Murata, Y; Nirasawa, S; Yamamoto, K; Ohara, S; Yusof, M N M; Ibrahim, W A and Mori, Y (2010). Old oil palm trunk: A promising source of sugars for bioethanol production. J. Biom. Bioenerg., 34: 1608-1613. 